Etnográfica

Revista do Centro em Rede de Investigação em

Antropologia

vol. 15 (3) | 2011

Vol. 15 (3)

\title{
Igor José de Renó Machado, Cárcere Público: \\ Processos de Exotização entre Brasileiros no Porto
}

\section{Beatriz Padilla}

\section{(2) OpenEdition \\ Journals}

Edição electrónica

URL: https://journals.openedition.org/etnografica/1088

DOI: 10.4000/etnografica.1088

ISSN: 2182-2891

\section{Editora}

Centro em Rede de Investigação em Antropologia

\section{Edição impressa}

Data de publição: 1 outubro 2011

Paginação: 605-607

ISSN: 0873-6561

\section{Refêrencia eletrónica}

Beatriz Padilla, «Igor José de Renó Machado, Cárcere Público: Processos de Exotização entre Brasileiros no Porto», Etnográfica [Online], vol. 15 (3) | 2011, posto online no dia 23 outubro 2011, consultado o 12 fevereiro 2022. URL: http://journals.openedition.org/etnografica/1088 ; DOI: https://doi.org/10.4000/ etnografica.1088

Etnográfica is licensed under a Creative Commons Attribution-NonCommercial 4.0 International License. 
Igor José de Renó Machado

CÁRCERE PÚBLICO:

\section{PROCESSOS DE EXOTIZAÇÃO}

ENTRE BRASILEIROS NO PORTO

Lisboa, ICS, 2009, 256 páginas.

Aceitei fazer a recensão deste livro com um duplo propósito: por um lado, ler novamente e de forma integral o que já tinha lido (e citado) tantas vezes ao longo dos últimos anos, devido ao meu trabalho de investigação em curso sobre a imigração brasileira em Portugal; por outro, identificar os contributos, leia-se vantagens e desvantagens, que a obra tem para oferecer hoje, em 2011.

O primeiro esclarecimento que deve ser feito é que o livro concretiza numa publicação, "finalmente", a tese de doutoramento do autor, defendida em 2003, a qual no processo editorial passou por uma operação de cosmética visual (leia-se de tradução para o português de Portugal, salvando-se os conteúdos críticos) e alguns recortes de imagens e fotografias que na versão original contribuíam para uma melhor ilustração dos diferentes tipos de exotização da brasilidade em Portugal, que, no fim, é um dos objetivos do livro.

Vários aspetos positivos devem ser destacados. Assim, esta obra é um master piece em vários microssentidos. Permite entender alguns aspetos do quotidiano dos imigrantes brasileiros que moravam no Porto no início do século XXI, especialmente daqueles que o autor denomina classe baixa, mesmo que a sua pertença a esta classe não tenha ficado totalmente esclarecida, salvo no contraste com outros grupos de brasileiros mais favorecidos, como dentistas e outros expatriados. Deixando de lado este pormenor, o dia a dia dos imigrantes brasileiros, segundo o autor, é dominado pela exotização que é consequência dos estereótipos dominantes na sociedade portuguesa, mas que eles próprios também assumem, até com "certa agência" (pelo menos quem pode), como uma estratégia de adaptação para conseguir um melhor posicionamento no mercado de trabalho portuense.

Sintetizando, os contributos teóricos que o autor oferece, e que giram em torno da exotização no contexto específico da imigração brasileira no Porto por volta de 2000, são: (i) o jogo da centralidade, (ii) a subordinação ativa, (iii) a identidade para o mercado. Estes conceitos, novos e criativos, são sem dúvida ferramentas que futuras investigações podem utilizar ou "testar", não só em Portugal, mas também em outros contextos migratórios onde os sujeitos são exotizados. Embora o "jogo da centralidade" e a "identidade para o mercado" sejam quase duas faces da mesma moeda, estando focados na inserção no mercado de trabalho, a categoria mais interessante, a meu ver, é a da subordinação ativa, já que ilustra como o imigrante adota e adapta o estereótipo dominante e como, muitas 
vezes nos casos apresentados, quem consegue reverter melhor a situação criada pela estereotipificação é aquele que geralmente tem menos poder (como pode ser um afro-brasileiro) nas sociedades dominadas pelos brancos (neste caso, tanto o Brasil como Portugal). Assim entram no jogo as ideias que os portugueses têm dos brasileiros e as que os próprios brasileiros têm sobre eles mesmos, incluindo a hierarquização (regional, racial) também existente no Brasil. Neste sentido, ser afro-brasileiro ou aproximar-se de um afro-brasileiro (especialmente baiano ou carioca) gera um valor acrescentado numa sociedade que aparentemente valoriza os aspetos culturais brasileiros associados à cultura afro (capoeira, música, religiões afro-brasileiras, etc.). Claro que estas hierarquias, e portanto a subordinação ativa descrita neste caso, só funcionam em contextos específicos, nos quais não se insere a maior parte da imigração brasileira em Portugal hoje; no entanto, resulta proveitoso refletir teórica e empiricamente sobre este facto.

Um outro aspeto relevante da obra de Machado é que deslumbra como peça etnográfica, especialmente nos capítulos em que partilha com o leitor o trabalho de campo. Neste sentido, pode ser pensada como referência metodológica sobre como fazer etnografia e como usar o diário de campo no processo de escrita. O estudo revela igualmente o posicionamento do autor no terreno (brasileiro, de classe média, etc.) que, por sua vez, determina uma dupla visão da realidade que estuda, ou seja, a de um brasileiro com os "pés” em Portugal (o que é conseguido graças à sua conexão com a família portuguesa de acolhimento ou adoção, que atua como uma ligação à terra, traduzindo as diferenças culturais às vezes impercetíveis) e que partilha a visão portuguesa da realidade sobre a imigração brasileira, situação que no conjunto possibilita uma melhor empatia. Esta dupla ancoragem é relevante na interpretação do fenómeno migratório, porque o autor revela como os seus interlocutores pertencem aos dois contextos, que se complementam e explicam, o de origem e o de destino.

Se bem que esta etnografia apresente aspetos muito positivos, como já foi ressaltado, é também importante apontar algumas críticas. Na minha opinião, um aspeto que deveria ter sido melhorado é sem dúvida a sua bibliografia. As referências a trabalhos posteriores a 2003 são escassas (salvo referências gerais à introdução dum livro publicado em 2007 em Portugal sobre a imigração brasileira), sobretudo se considerarmos a prolífica produção sobre o tema desde então. A mesma crítica pode ser feita em relação à falta de atualização da legislação, especialmente porque mudou repetidamente, tendo consequências específicas para os cidadãos brasileiros residentes em Portugal. Neste sentido, uma atualização de dados, legislação e referências teria sido sem dúvida uma mais-valia, permitindo fazer uma ponte entre a realidade longínqua descrita no livro e o presente.

A escolha do trabalho de campo não é neutra. $\mathrm{O}$ facto de este estar focado nos bares e lugares/momentos de lazer, mesmo que seja enriquecedor, conduz o leitor a pensar que a vida dos brasileiros, o seu dia a dia, é ainda mais exotizado, ao não permitir perceber, salvo em casos específicos, como decorre um dia "normal" do imigrante. Podemos perguntar-nos até que ponto o "jogo da centralidade" e a "identidade para o mercado" marcam todos os aspetos da vida como imigrante, ou se viver virado para o mercado só reflete a experiência de alguns brasileiros, talvez daqueles mais ligados ao mercado artístico-cultural e, na altura, àquelas ocupações onde o atendimento ao público era percebido como central. Contudo, o enfoque inovador sobre os momentos lúdicos, o tempo livre e a socialização do imigrante justificam a limitação 
que essa escolha impõe. Por outro lado, ainda pode salientar-se que, mesmo que o autor fale da imigração brasileira no Porto, as experiências focam mais o ponto de vista do imigrante no masculino, salvo o caso das mulheres que socializam nos mesmos bares e que trabalham no mercado do sexo, mas essas não podem ser estendidas a todas as mulheres brasileiras.

Finalmente, os contributos mais interessantes do livro, especialmente por serem mais críticos, inovadores e comparativos e por não terem perdido atualidade, são o capítulo 5 e o anexo sobre o exotismo. Enquanto o capítulo 5 analisa a contemporaneidade da lusofonia, como fenómeno colonial por oposição ao "pós-colonial”, como coluna vertebral do pensamento luso (salvo

Alice Duarte

\section{EXPERIÊNCIAS DE CONSUMO: ESTUDOS DE CASO NO INTERIOR DA CLASSE MÉDIA}

Porto, U. Porto Editorial, 2009, 226 páginas.

\section{Experiências de Consumo: Estudos de Caso no} Interior da Classe Média foi publicado em 2009 e corresponde a uma parte da tese de doutoramento defendida pela autora, Alice Duarte, em janeiro de 2008. O trabalho de terreno que deu origem ao estudo decorreu entre 2002 e 2004. Em 2002 Alice Duarte publicou, nesta mesma revista, um texto intitulado "Daniel Miller e a antropologia do consumo" e, em junho de 2010 , um outro, também correspondente a uma parte da tese, intitulado "A antropologia e o estudo do consumo: revisão crítica das suas relações e possibilidades". Este mapeamento poucas exceções), e explica as hierarquias étnico-raciais vigentes em Portugal, o anexo apresenta uma análise comparativa muito interessante sobre a situação e posicionamento dos imigrantes brasileiros em outros contextos migratórios, como a Argentina, os Estados Unidos e o Japão, os quais mudam segundo os imigrantes sejam ou não exotizados, permitindo ao leitor entender melhor a posição dos brasileiros em Portugal.

Num balanço final, a qualidade da discussão e debate que Cárcere Público traz ao fenómeno das migrações, especialmente no contexto português, valoriza esta publicação tardia.

Beatriz Padilla

CIES-IUL temporal serve a tarefa de colocar a obra aqui recenseada no interior da produção antropológica nacional e internacional: no início da década de 2000 a autora faz uma aproximação teórica aos então recentes (mas já em clara fase de expansão para as academias de países periféricos) estudos do consumo em antropologia e inicia uma investigação que será publicada em livro no fim da mesma década (o segundo volume O Consumo para os Outros - foi publicado já em maio de 2011, também pela U. Porto Editorial). Este foi, grosso modo, o arco de tempo necessário para que o novo campo de estudo - investido por vários investigadores - tomasse forma em Portugal. A produção académica é hoje muito veloz, mas não prescinde dos tempos necessários à sua boa realização e estes parecem ser mais longos que aqueles que presidem ao funcionamento do real: neste caso, estamos face a uma obra indispensável para compreender 